\title{
Altered glycosylation profile of purified plasma ACT from Alzheimer's disease
}

\author{
Manuela lanni ${ }^{\dagger}$, Marcella Manerba ${ }^{\dagger}$, Giuseppina Di Stefano, Elisa Porcellini, Martina Chiappelli, Ilaria Carbone, \\ Federico Licastro*
}

From Predictive diagnostics and prevention of chronic degenerative disease

Bologna, Italy. 4 December 2009

\begin{abstract}
Background: Alzheimer's disease (AD) is one of the most frequent cause of neurodegenerative disorder in the elderly. Inflammation has been implicated in brain degenerative processes and peripheral markers of brain AD related impairment would be useful. Plasma levels of alpha-1-antichymotrypsin (ACT), an acute phase protein and a secondary component of amyloid plaques, are often increased in AD patients and high blood ACT levels correlate with progressive cognitive deterioration. During inflammatory responses changes in the micro-heterogeneity of ACT sugar chains have been described.
\end{abstract}

Methods: N-Glycanase digestion from Flavobacterium meningosepticum (PNGase F) was performed on both native and denatured purified ACT condition and resolved to Western blot with the purpose to revealed the ACT de-glycosylation pattern.

Further characterization of the ACT glycan profile was obtained by a glycoarray; each lectin group in the assay specifically recognizes one or two glycans/epitopes. Lectin-bound ACT produced a glyco-fingerprint and mayor differences between AD and controls samples were assessed by a specific algorithms.

Results: Western blot analysis of purified ACT after PNGase F treatment and analysis of sugar composition of ACT showed significantly difference in "glyco-fingerprints" patterns from controls (CTR) and AD; ACT from AD showing significantly reduced levels of sialic acid. A difference in terminal GlcNac residues appeared to be related with progressive cognitive deterioration.

Conclusions: Low content of terminal GICNac and sialic acid in peripheral ACT in AD patients suggests that a different pattern of glycosylation might be a marker of brain inflammation. Moreover ACT glycosylation analysis could be used to predict AD clinical progression and used in clinical trials as surrogate marker of clinical efficacy.

\section{Background}

Alzheimer's disease (AD) is a neurodegenerative disorder clinically defined by progressive impairment of memory and cognitive functions. Brain pathology hallmarks of AD are extra-cellular amyloid plaques and intracellular neurofibrillary tangles, along with hyperactive microglia, activated astrocytes, degenerating neurons and synapsis loss [1].

\footnotetext{
* Correspondence: federico.licastro@unibo.it

† Contributed equally

Department of Experimental Pathology, School of Medicine, University of Bologna, 14 San Giacomo St, 40126 Bologna, Italy

Full list of author information is available at the end of the article
}

Alpha-1-antichymotrypsin (ACT) is a secondary component of amyloid plaques [2]; it belongs to the superfamily of Serpins (serine protease inhibitors) and is also known as SERPINA3 [3]. ACT is synthesized in the liver and in other tissues, including lungs and brain. In the brain ACT is produced by activated astrocytes found near brain beta-amyloid (A $\beta)$ deposits [4]. It has been suggested that ACT binds $A \beta$ peptide and affects the rate of amyloid fibril formation in vitro[5,6]. Findings from mouse models of $A D$ have also shown that ACT over-expression promotes $A \beta$ peptide deposition in the brain of $\mathrm{AD}$ animal models [7] and affected their cognitive performances [8]. More recently, ACT has

\section{Biomed Central}

(c) 2010 lanni et al; licensee BioMed Central Ltd. This is an open access article distributed under the terms of the Creative Commons Attribution License (http://creativecommons.org/licenses/by/2.0), which permits unrestricted use, distribution, and reproduction in any medium, provided the original work is properly cited. 
been shown to influence TAU protein phosphorylation and apoptosis in neuronal cells [9].

Interleukin- $\alpha$ (IL-1 $\alpha)$, IL-1 $\beta$, IL-6, tumor necrosis factor $\alpha$ (TNF- $\alpha$ ) and other cytokines are up-regulated and are associated with AD lesions. The inflammatory cytokines IL- 1, IL- 6 , and TNF- $\alpha$ are produced by both activated microglia and astrocytes. Moreover, IL- 6 and oncostatin $\mathrm{M}$ have been reported to modulate ACT production in brain astrocytes [10]. These data have suggested the notion that ACT might be a critical factor affecting both neurodegenerative process induced by amyliod deposition and brain inflammatory processes. The association of gene variations in ACT and other cytokine genes with the increased risk of AD has further reinforced the above hypothesis [11].

Whether peripheral levels of ACT may be of practical use, as AD biomarker or an indicator of the disease clinical progression, remains an open question. In fact, after the initial reports of increased blood and CSF ACT concentrations in AD patients [12-14], several studies measured ACT concentrations in blood samples drawn from subjects with $\mathrm{AD}$, with other forms of dementias, and control subjects. Findings from these studies have produced conflicting results; some investigations confirming increased serum ACT levels $[12,15,16]$ others showing normal ACT blood levels in AD $[17,18]$. Recent findings indeed showed that peripheral blood ACT levels were increased in AD patients or subjects with cognitive alteration and no dementia and high ACT levels correlated with progressive cognitive deteriorations [19]. These data paralleled other findings showing that ACT blood levels correlated with cognitive performances in elderly without dementia [20]. Different techniques for ACT detection, different criteria for the selection of controls and AD patients or small numbers of cases and controls included in the studies may account for contradictory results regarding the association of abnormal ACT plasma levels with AD. Moreover, alterations in molecular forms of ACT present in tissues and/or blood might also account for increased variability of ACT detection in $\mathrm{AD}$ and controls. However, no investigation has focused upon ACT molecular rearrangement in AD.

ACT plays a role in the modulation of brain amyloid deposition and immune responses, both processes are thought to be important contributors to the pathogenesis of AD [21]. Inflammatory states are usually associated with changes in the glycosylation pattern of acute phase proteins $[22,23]$. ACT is a glycoprotein and carbohydrates accounts approximately for $25 \%$ of its molecular weight. The sugar chain composition of ACT was studied by affinity immune-electrophoresis with Concanavalin A [24], by high resolution ${ }^{1} \mathrm{H}-\mathrm{NMR}$ spectroscopy [25] and, more recently, by mass spectrometry techniques [26]. ACT contains six N-glycosylation sites and shows four oligosaccharide side-chains with disialyl diantennary and trisialyl triantennary type glycan structures with traces of disialylated triantennary oligosaccharides. Studies from other biology fields showed that inflammatory responses causes changes in the microheterogeneity of ACT sugar chains. Such changes were observed in several disease states, such as prostate cancer, myocardial infarction, ovary cancer, septic inflammation, metastatic breast cancer, connective tissue disease and pulmonary sarcoidosis [24,25,27-29] .

In AD altered glycosilation pattern of presenilin-1, a molecule forming the catalytic core of the $\gamma$-secretase complex and able to generate amyloidogenic peptides [30] and an abnormal glycosylation of reelin, a glycoprotein essential for the correct cyto-architectonic organization of the developing CNS, were previously shown [31].

No data on plasma ACT glycosylation patterns in AD are on record. Here we have shown that glycosylation pattern of this molecule from the peripheral blood of $\mathrm{AD}$ patients and healthy controls is partially different.

\section{Methods \\ Patients}

The control plasma samples were from the "Conselice Study of brain aging" [32] and the demented patients were also from a different Northern Italy clinical longitudinal study, where AD patients were followed up for two years and their cognitive performances recorded. Patients and controls were Caucasians and informed consent from each control and $\mathrm{AD}$ relative was obtained.

Diagnosis of probable AD was performed according to standard clinical procedure and followed the NINCDS/ ADRDA and DSM-IV-R criteria [33,34]. Cognitive performances were measured according to MMSE. Cognitive decline during the 2 year longitudinal follow up in AD patients was also assessed by the MMSE scores, according to the method suggested elsewhere [35].

\section{Purification of ACT from plasma of CTR and AD}

Plasma samples from CTR and AD patients with comparable ACT levels were chosen. ACT levels in plasma were measured by using a competitive ELISA assay, as described elsewhere [19]. Plasma samples from 20 CTR or $19 \mathrm{AD}$ patients were pooled in 2 distinct experimental sets (CTR 1 and 2 and AD 1 and 2, respectively). All experiments were performed using purified ACT obtained from these plasma sample pools.

Purification of ACT was performed by affinity chromatography using Hitrap NHS-activated HP columns (1 ml) (GE Lifesciences, Milan). $10 \mathrm{mg}$ of sheep antihuman ACT antibody (AbCam, Cambridge) was coupled to the column matrix according to the manufacturer's instructions. 
Pooled plasma samples $(100 \mu \mathrm{l})$ containing about 70 $\mu \mathrm{g}$ ACT were diluted to $10 \mathrm{ml}$ with $\mathrm{PBS}$, filtered through a $0.45 \mu \mathrm{m}$ filter and applied to the column. Each sample was left re-circulating for $2 \mathrm{~h}$ at room temperature using a peristaltic pump at a flow rate of 0.2 $\mathrm{ml} / \mathrm{min}$. Thereafter, the column was washed with $10 \mathrm{ml}$ of PBS and bound ACT was eluted with $0.2 \mathrm{M}$ glycine, $\mathrm{pH} 2.8$; the purified protein was immediately neutralized with $5 \mathrm{~N} \mathrm{NaOH}$ and dialyzed against $\mathrm{H}_{2} \mathrm{O}$ and concentrated under reduced pressure.

\section{Assessment of purified ACT concentration by sandwich ELISA assay}

96 well maxisorp plates (Nunc, Milan) were coated with $100 \mu \mathrm{l}$ of sheep anti-human ACT antibody (AbCam, Cambridge), diluted $1: 1000$ in $50 \mathrm{mM} \mathrm{Na} / \mathrm{CO}_{3} \mathrm{pH} 8.5$, incubated overnight at $4{ }^{\circ} \mathrm{C}$ and washed. If not otherwise specified, washing of plates was always performed with $4 \times 200 \mu \mathrm{l} /$ well of PBS+0,05\% Tween 20x (PBST) and incubation steps throughout the assay always lasted $2 \mathrm{~h}$, at $37^{\circ} \mathrm{C}$, with shaking. After washing, plates were incubated with $100 \mu \mathrm{l} /$ well of PBST $+5 \%$ BSA and washed again.

Thereafter, $100 \mu \mathrm{l}$ of commercially available ACT (Sigma, Milan) (dissolved in PBST $+1 \%$ BSA), in several dilutions ranging from 0 to $200 \mathrm{ng} / \mathrm{ml}$ to generate a standard curve, and test samples were added to the plate wells. After incubation and washing, plates were incubated with primary antibody $(100 \mu \mathrm{l} /$ well of rabbit anti-human ACT antibody (Dako, Milan), diluted 1:1000 in PBST $+1 \% \mathrm{BSA}$ ) and secondary HRP-conjugated antibody (goat anti-rabbit-HRP (Santa Cruz, Heidelberg), diluted 1:1000 in PBST+1\% BSA).

Following the usual PBST washes, an additional wash with $200 \mu \mathrm{l}$ of PBS without Tween was performed and $100 \mu$ of peroxidase substrate (ABTS) (Roche, Milan) diluted in ABTS buffer (Roche, Milan) was added to the wells.

Absorbance was recorded by an automatic ELISA reader at $405 \mathrm{~nm}$ (Biorad, Milan).

\section{De-glycosylation by N-Glycanase digestion of purified ACT}

N-Glycanase from Flavobacterium meningosepticum (PNGase F) was used (BioLabs, Milan). De-glycosylation was performed on both native and denatured purified ACT.

Reaction in native conditions was performed by incubating $1 \mu \mathrm{g}$ of purified ACT with $500 \mathrm{U}$ of PNGase F in $50 \mathrm{mM}$ sodium phosphate $\mathrm{pH} 7.5,1 \% \mathrm{NP}-40$ at $37^{\circ} \mathrm{C}$ for 1 and $3 \mathrm{~h}$.

Denaturation of purified ACT was obtained by heating the protein at $100^{\circ} \mathrm{C}$ for $10 \mathrm{~min}$ in the presence of $0.5 \%$ SDS and $40 \mathrm{mM}$ dithiothreitol (DTT). After denaturation, ACT was reacted with PNGase F, as described above.

De-glycosylated ACT samples were resolved on a $10 \%$ SDS-polyacrylamide gel, blotted on a PVDF membrane, visualized by immune reaction with a specific antibody (rabbit anti-human ACT (Dako, Milan) and revealed by a Cy5-labelled secondary antibody (GE Lifesciences, Milan).

\section{Glycan composition analysis of purified ACT}

The glycan profile of purified ACT samples was obtained by using the Qiagen Qproteome ${ }^{\mathrm{TM}}$ GlycoArray. Briefly, $5 \mu \mathrm{g}$ of purified ACT were absorbed onto the surface of the GlycoArray slide, following the manufacturer's instructions. Lectin-bound ACT was revealed by immune reaction using the rabbit anti-human ACT antibody (QIAGEN, Dako, Milan) and the Cy5-labelled secondary antibody (GE Lifescience, Milan). The entire process was performed in parallel without samples on a separate control array. At the end of the procedure, array slides were scanned and analyzed using the Scann Array 4000 scanner (Packard Biochip Technologies, Milan). Array image data were analyzed using the Qproteome Glycoarray Analysis Software (QIAGEN), which calculates the "glyco-fingerprint" of the sample protein by subtracting the control array signals from the experimental sample array signals. Fingerprint deconvolution was performed by algorithms using rule-based technology calibrated to a wide range of standard proteins. Each lectin group in the assay specifically recognizes one or two glycans/epitopes, although a degree of interdependence between these groups is present. This algorithm according to manufacturer calculates relative abundance of glycan epitopes and provides array-binding information on the proportion of various features within a glycoform population.

\section{Results}

Clinical, cognitive and epidemiological variables along with number of subjects, ACT plasma levels, purified pooled ACT samples, age, gender, cognitive status assessed by MMSE scores at the time of clinical diagnosis and two years later from controls (CTR) and AD are summarized in Table 1 . The AD 1 showed a higher cognitive deterioration during a 2 year follow up than the AD 2. Plasma samples from 2 different group of control (CTR 1 and 2) and AD patients (AD 1 and 2) were used for the purification of ACT and the biochemical analysis. Mean plasma ACT levels between 2 groups of controls and AD patients were comparable, as well as those of the collected ACT after the purification procedures.

Figure 1 shows Western Blot analysis of purified ACT from CTR 1 and 2 or AD 1 and 2 treated with PNGase F. De-glycosylation of native purified ACT form both 
Table 1 Epidemiological and clinical features from investigated subjects

\begin{tabular}{|c|c|c|c|c|}
\hline & CTR 1 & CTR 2 & $\mathrm{AD} 1$ & AD 2 \\
\hline $\mathrm{N}^{\circ}$ of samples & 10 & 10 & 9 & 10 \\
\hline $\mathrm{ACT}$ mean $(\mu \mathrm{g} / \mathrm{ml})$ & 763 & 789 & 695 & 876 \\
\hline $\mathrm{ACT}$ purify $(\mu \mathrm{g} / \mathrm{ml})$ & 26 & 38 & 27 & 32 \\
\hline Age & 73 & 75 & 80 & 77 \\
\hline Gender & $9 F-1 M$ & $4 F-6 M$ & $7 F-2 M$ & $7 F-3 M$ \\
\hline Evolution & $4 S-11-5 N A$ & $2 S-5 I-3 N A$ & $2 F-6 I-1 S$ & $1 F-5 I-4 S$ \\
\hline MMSE time 0 & 28 & 28 & 19 & 19 \\
\hline MMSE after 2 year follow up & 27 & 26 & 13 & 18 \\
\hline
\end{tabular}

Number of subjects, ACT plasma levels, purified ACT of subjects's pool, age, gender, group of cognitively state, MMSE scores at the beginning of the study and two years later are summarized in this table.

CTR and AD samples resolved into three protein bands and no qualitative differences were observed between CTR and AD. On the contrary, when PNGase F treatments was performed on denatured purified ACT, four bands were detected in both CTR 1 and 2, whereas ACT from AD samples resolved again into three bands. Semi quantitative evaluation of fluorescence band intensity from Figure 1 is reported in Table 2. Total fluorescence from ACT PAGE electrophoresis and western blot analysis in band 1 from CTR and AD was comparable (CTR 1 = 37977; AD 1 = 44469; CTR 2 = 35449; AD 2 = 23722). Results regarding total fluorescence and its percentage in band 1, 2 and 3 (native) and 1, 2, 3 and 4 (denatured) are reported in Table 2 . Some difference was observed in native samples from CTR 2 and AD 2 after 3 hours of incubation with PNGase $F$ enzyme. Under mild denaturing treatment band 4 was never detected in AD 1 and AD 2 and strong difference in fluorescence intensity in band 1, 2 and 3 after 3 hours of PNGase F digestion were found. Moreover, fluorescence intensity in band 1, 2 and 3 from AD 1 and AD 2 was quite different from those of CTR 1 and CTR 2, especially after 3 hour treatment. In fact, in these condition both total fluorescence intensity and its percentage, were higher in bands 1 and 2 from AD 1 and AD 2 samples than those detected in CTR 1 and/or CTR 2.

Further analysis of sugar composition in purified ACT from CTR 1 and 2 or AD 1 and 2 was performed by using the Qproteome ${ }^{\mathrm{Tm}}$ GlycoArray kit. This glyco-array consisted of 24 lectins covering a large pattern of glycan specificity. Binding of a glycoprotein to the array results in a characteristic fingerprint pattern that is highly sensitive to the glycan structure and composition. Glycan structure semi-quantitatively detectable by the array include: $\mathrm{N}$-glycans (bi-antennary, tri/tetra antennary, high mannose, sialic acid, terminal $\mathrm{N}$-acetyl glucosamine (GlcNac), terminal $\mathrm{N}$-acetyl galactosamine (GalNac) and bisecting GlcNac and presence or absence of O-glycans. The fingerprint is interpreted by proprietary knowledge- based algorithms to produce the glycoanalysis results, a list of epitopes and their relative abudance.

Fingerprint data, analyzed by the Qproteome ${ }^{\mathrm{Tm}}$ GlycoArray software, produced a detailed profile of ACT glycosylation status and a glycan epitope prediction pattern by the specific algorithm (Table 3). The Qproteome $^{\mathrm{rm}}$ GlycoArray method provides four levels quantification output for most epitopes: not Detected $=$ up to $10 \%$, low $=11-30 \%$, medium $=31-70 \%$, high $=71$ $100 \%$ and a qualitative glycan profile for other epitopes (detected/not detected). Quantitative difference in purified ACT lectin reactivity between the experimental sets, i.e. Purified ACT from AD 1 and 2 showed significantly reduced levels of sialic acid when compared to those from CTR 1 and 2. Moreover, a difference in terminal GlcNac residues was found between AD 1 and AD 2 groups. It is interesting to note that AD 1 showed a faster cognitive deterioration than $\mathrm{AD} 2$ in a 2 years follow up. In fact, as shown in Table 1, AD 1 patients loosed 5 points in the MMSE score and AD 2 patients only 1 point.

\section{Discussion}

Glycosylation is a versatile biochemical mechanism and one of the most abundant post-translational modification of protein; however, glycosylation of proteins is not a template driven process, is difficult to predict [36] and affects molecule stability, resistance to proteolysis, solubility and molecule functional activity. Therefore, this protein modification may play a role in affecting biological activity of molecules with a special role in the metabolic events related to neuro-degeneration and AD.

ACT is a glycoprotein and carbohydrate content reach $24 \%$ of molecular weight. This acute phase proteins is mainly synthesized by the liver, however, other tissues are able to produce and release this molecule. In fact, astrocytes synthesized and release ACT and increased levels of this protein have been found in the brain, CSF and blood from AD patients $[15,19,37]$. ACT levels in 


\section{Panel A}

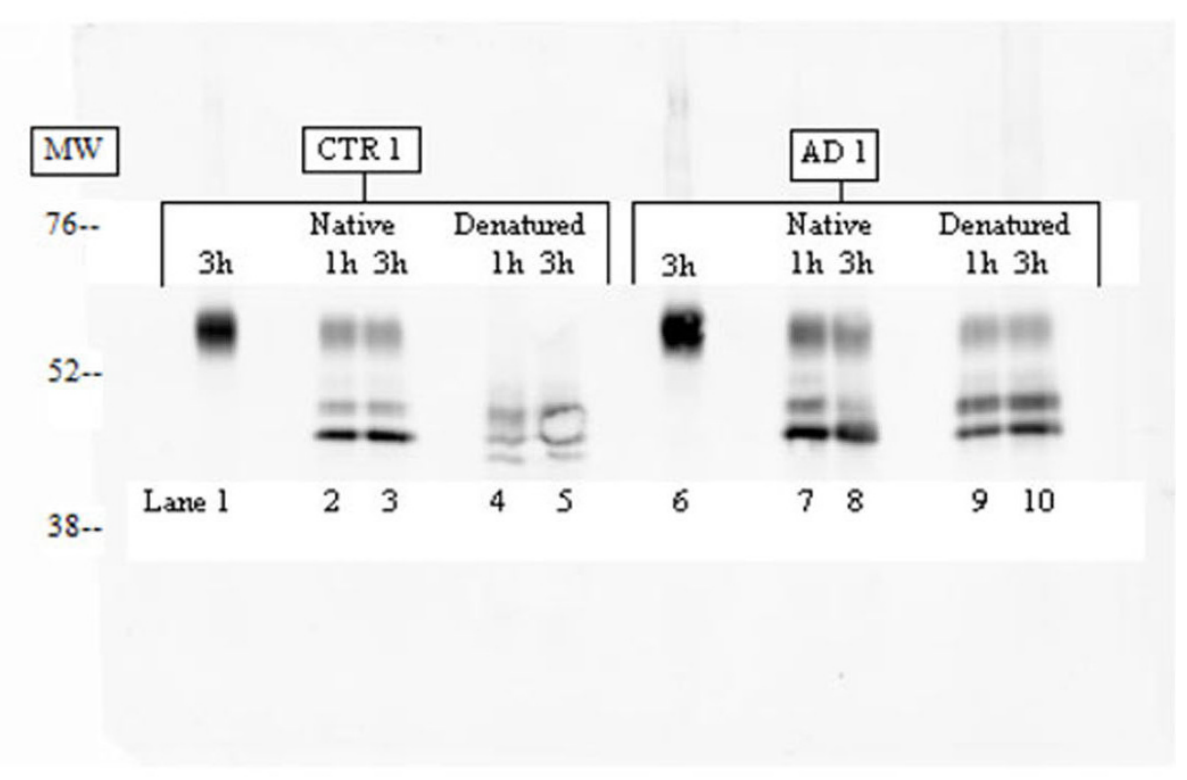

Panel B

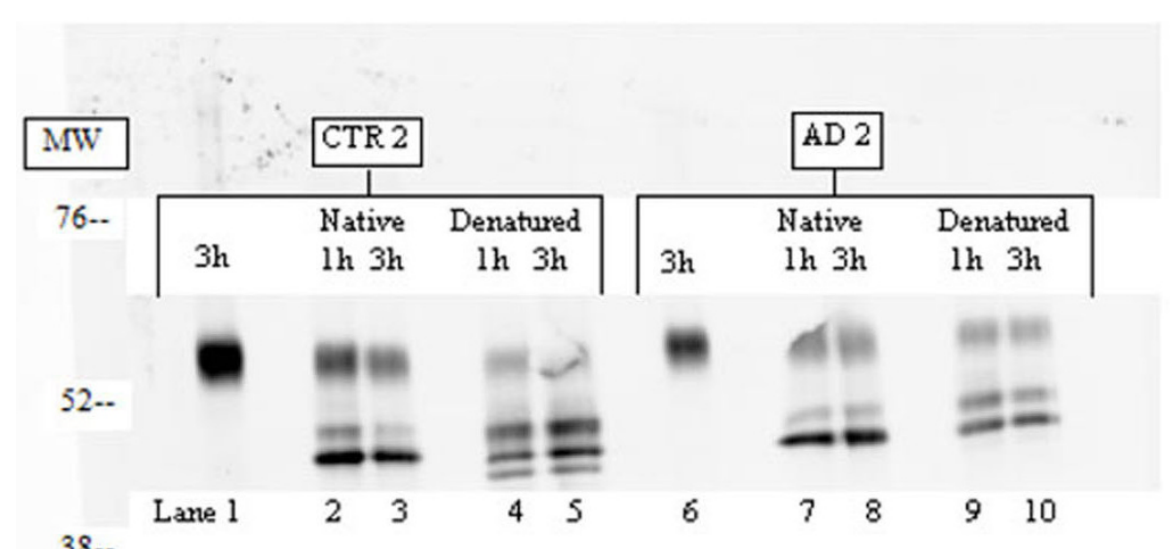

Figure 1 Western blot analysis of ACT after PNGase F digestion. Panel A. Lane 1, CTR 1 incubated 3 hours without PNGaseF; lane 2, CTR 1 in condition Native incubated for 1 h; lane 3, CTR 1 Native incubated for 3 h; lane 4, CTR 1 Denatured incubated for 1 h; lane 5, CTR 1 Denatured incubated for 3 h; lane 6, AD 1 incubated 3 hours without PNGaseF; lane 7, AD 1 Native incubated for 1 h; lane 8, AD 1 Native incubated for 3 h; lane 9, AD 1 Denatured incubated for 1 h; lane 10 AD1 Denatured incubated for 3 h. Panel B refers to CTR 2 and AD 2 with the same treatment. MW= molecular weight. 
Table 2 Fluorescence intensity analysis after PNGase F treatment

\begin{tabular}{|c|c|c|c|c|c|c|c|c|}
\hline \multirow{2}{*}{$\frac{\text { PANEL A }}{\text { Band }}$} & \multicolumn{4}{|c|}{ CTR 1} & \multicolumn{4}{|c|}{ AD 1} \\
\hline & Native $11 \mathrm{~h}$ & Native $33 \mathrm{~h}$ & Denatured $1 \mathrm{~h}$ & Denatured $3 \mathrm{~h}$ & Native $11 \mathrm{~h}$ & Native $33 \mathrm{~h}$ & Denatured $1 \mathrm{~h}$ & $\begin{array}{c}\text { Denatured } \\
3 \mathrm{~h}\end{array}$ \\
\hline 1 & $\begin{array}{c}12271 \\
(41.2 \%)\end{array}$ & $\begin{array}{c}11658 \\
(38.6 \%)\end{array}$ & $\begin{array}{l}8608 \\
(57 \%)\end{array}$ & $\begin{array}{c}978 \\
(5.5 \%)\end{array}$ & $\begin{array}{c}20528 \\
(40.5 \%)\end{array}$ & $\begin{array}{c}16066 \\
(37.4 \%)\end{array}$ & $\begin{array}{c}10821 \\
(30.5 \%)\end{array}$ & $\begin{array}{c}10480 \\
(25.3 \%)\end{array}$ \\
\hline 2 & $\begin{array}{c}5297 \\
(17.8 \%)\end{array}$ & $\begin{array}{c}5272 \\
(17.4 \%)\end{array}$ & $\begin{array}{l}4313 \\
(28 \%)\end{array}$ & $\begin{array}{c}9264 \\
(52.6 \%)\end{array}$ & $\begin{array}{l}10135 \\
(20 \%)\end{array}$ & $\begin{array}{c}5651 \\
(13.1 \%)\end{array}$ & $\begin{array}{c}12959 \\
(36.6 \%)\end{array}$ & $\begin{array}{c}15418 \\
(37.1 \%)\end{array}$ \\
\hline 3 & $\begin{array}{l}12229 \\
(41 \%)\end{array}$ & $\begin{array}{l}13257 \\
(44 \%)\end{array}$ & $\begin{array}{l}2240 \\
(15 \%)\end{array}$ & $\begin{array}{c}4689 \\
(26.6 \%)\end{array}$ & $\begin{array}{c}19972 \\
(39.5 \%)\end{array}$ & $\begin{array}{l}21315 \\
(49.5 \%)\end{array}$ & $\begin{array}{c}11668 \\
(32.9 \%)\end{array}$ & $\begin{array}{c}15594 \\
(37.6 \%)\end{array}$ \\
\hline 4 & & & & $\begin{array}{c}2702 \\
(15.3 \%)\end{array}$ & & & & \\
\hline PANEL B & \multicolumn{4}{|c|}{ CTR 2} & \multicolumn{4}{|c|}{$A D 2$} \\
\hline Band & Native $11 \mathrm{~h}$ & Native $33 \mathrm{~h}$ & Denatured $1 \mathrm{~h}$ & Denatured $3 \mathrm{~h}$ & Native $11 \mathrm{~h}$ & Native $33 \mathrm{~h}$ & Denatured $1 \mathrm{~h}$ & $\begin{array}{c}\text { Denatured } \\
3 \mathrm{~h}\end{array}$ \\
\hline 1 & $\begin{array}{c}18537 \\
(46.7 \%)\end{array}$ & $\begin{array}{c}12721 \\
(44.9 \%)\end{array}$ & $\begin{array}{c}6925 \\
(25.1 \%)\end{array}$ & $\begin{array}{c}5234 \\
(15.7 \%)\end{array}$ & $\begin{array}{c}10371 \\
(44.4 \%)\end{array}$ & $\begin{array}{c}10937 \\
(37.2 \%)\end{array}$ & $\begin{array}{c}6649 \\
(37.1 \%)\end{array}$ & $\begin{array}{c}5579 \\
(36.7 \%)\end{array}$ \\
\hline 2 & $\begin{array}{c}6293 \\
(15.9 \%)\end{array}$ & $\begin{array}{l}2825 \\
(10 \%)\end{array}$ & $\begin{array}{c}11136 \\
(40.4 \%)\end{array}$ & $\begin{array}{c}14381 \\
(43.3 \%)\end{array}$ & $\begin{array}{c}2916 \\
(12.5 \%)\end{array}$ & $\begin{array}{c}4048 \\
(13.8 \%)\end{array}$ & $\begin{array}{c}5527 \\
(30.8 \%)\end{array}$ & $\begin{array}{c}3913 \\
(25.8 \%)\end{array}$ \\
\hline 3 & $\begin{array}{c}14817 \\
(37.4 \%)\end{array}$ & $\begin{array}{c}12804 \\
(45.1 \%)\end{array}$ & $\begin{array}{c}6094 \\
(22.1 \%)\end{array}$ & $\begin{array}{c}10005 \\
(30.1 \%)\end{array}$ & $\begin{array}{c}10083 \\
(43.1 \%)\end{array}$ & $\begin{array}{l}14385 \\
(49 \%)\end{array}$ & $\begin{array}{c}5759 \\
(32.1 \%)\end{array}$ & $\begin{array}{c}5706 \\
(37.5 \%)\end{array}$ \\
\hline 4 & & & $\begin{array}{c}3428 \\
(12.4 \%)\end{array}$ & $\begin{array}{c}3632 \\
(10.9 \%)\end{array}$ & & & & \\
\hline
\end{tabular}

Band fluorescence intensity after PNGase F treatment (see Western Blot bands in figure 1, panels A and B).

the blood markedly increases after tissue damages or infections [38]. We already postulated that a proportion of plasma ACT in AD might derive from the brain as a by-product of neurodegenerative processes and inflammation in the central nervous system [39]. As for other glycoproteins, micro-heterogeneity of ACT may be ascribed to differences in carbohydrate structure and indeed different patterns of ACT micro-heterogeneity has been shown in different diseases [40,41].

Table 3 Glycan epitope pattern of Cy5 labeled ACT

\begin{tabular}{|c|c|c|c|c|}
\hline Glycan epitope & CTR 1 & AD 1 & CTR 2 & $A D 2$ \\
\hline \multicolumn{5}{|l|}{ N-linked: } \\
\hline Bi Antennary & $\begin{array}{c}\text { Not } \\
\text { Detected }\end{array}$ & $\begin{array}{c}\text { Not } \\
\text { Detected }\end{array}$ & $\begin{array}{c}\text { Not } \\
\text { Detected }\end{array}$ & $\begin{array}{c}\text { Not } \\
\text { Detected }\end{array}$ \\
\hline $\begin{array}{l}\text { Tri/Tetra } \\
\text { Antennary }\end{array}$ & High & High & High & High \\
\hline High Mannose & $\begin{array}{c}\text { Not } \\
\text { Detected }\end{array}$ & $\begin{array}{c}\text { Not } \\
\text { Detected }\end{array}$ & $\begin{array}{c}\text { Not } \\
\text { Detected }\end{array}$ & $\begin{array}{c}\text { Not } \\
\text { Detected }\end{array}$ \\
\hline Sialic Acid & High & Medium & High & Medium \\
\hline Terminal GlcNAc & Low & Low & Low & $\begin{array}{c}\text { Not } \\
\text { Detected }\end{array}$ \\
\hline Terminal GalNAC & $\begin{array}{c}\text { Not } \\
\text { Detected }\end{array}$ & $\begin{array}{c}\text { Not } \\
\text { Detected }\end{array}$ & $\begin{array}{c}\text { Not } \\
\text { Detected }\end{array}$ & $\begin{array}{c}\text { Not } \\
\text { Detected }\end{array}$ \\
\hline Bisecting GlcNAc & $\begin{array}{c}\text { Not } \\
\text { Detected }\end{array}$ & $\begin{array}{c}\text { Not } \\
\text { Detected }\end{array}$ & $\begin{array}{c}\text { Not } \\
\text { Detected }\end{array}$ & $\begin{array}{c}\text { Not } \\
\text { Detected }\end{array}$ \\
\hline O-Glycans & $\begin{array}{c}\text { Not } \\
\text { Detected }\end{array}$ & $\begin{array}{c}\text { Not } \\
\text { Detected }\end{array}$ & $\begin{array}{c}\text { Not } \\
\text { Detected }\end{array}$ & $\begin{array}{c}\text { Not } \\
\text { Detected }\end{array}$ \\
\hline
\end{tabular}

Glycan profile produced for ACT using the Qproteome Glycoarray method. $\mathrm{ND}=$ not detected (up to 10\%); Low=11-30\%; Medium=31-70\%; High=71-100\%.
To obtain usable level of purified ACT, samples from $\mathrm{AD}$ or control were pooled; plasma samples showing comparable levels of this serpin, as assessed by competitive ELISA, i.e. moderately high ACT levels, were chosen. This step is relevant, since plasma levels of ACT and other serpins increase in different pathological conditions; however, in this investigation both patients controls were free from cancer, infections and inflammatory diseases.

Here we showed that after partial denaturation, purified ACT from AD plasma samples were less sensitive to enzymatic digestion by N-glycanase than ACT from plasma samples of healthy donors. This first observation suggested a different glycosylation pattern in ACT form AD patients, since denaturation was shown to increase deglycosylation by glycanase [25]. Different deglycosylation patterns of denatured ACT between AD and CTR may be ascribed to differentially presence of fucose residues linked $\alpha(1-3)$ to ASN bound $\mathrm{N}$-acetylglucosamine that resistant to PNGase $\mathrm{F}$ action.

Purified ACT was then analysed by a lectin array specifically developed for investigating protein glycan content and composition [42]. This analysis resulted in a partially different pattern of glycan profiles between $\mathrm{ACT}$ from $\mathrm{AD}$ and controls; sialic acid content being different between AD and CTR.

This alteration may have several explanations. For instance, a proportion of circulating ACT in AD plasma may derive from other tissues than liver, possibly the 
brain and this molecules might show a different glycosylation signature.

On the other hand, we can not exclude another interpretation suggesting that altered ACT glycan profile from $\mathrm{AD}$ samples may reflect a generalized impairment of glycosylation processes involving other glycoproteins. In fact, it has previously shown that reelin, a glycoprotein essential for the correct cyto-architecture organisation of developing brain and involved in signalling pathways linked to neuro-degeneration in several human diseases, were increased in the brain from neurological disorders and showed a different glycosylation patterns in plasma from AD [31]. Moreover, acetylcholine esterase from $\mathrm{AD}$ samples analyzed by lectin binding activity showed different binding properties when compare with those from controls [43].

Also our data showed a slight but significant difference in the two AD sets. AD 1 showing higher fluorescence intensity in terminal GlcNac and sialic acid than $A D$ 2. Patients belonging to the AD 1 group showed a faster cognitive deterioration rate in a 2 year follow up. Overall our data suggest altered sialic acid content in $\mathrm{ACT}$ from AD samples and the potential presence of focuse residues in the denatured ACT from CTR than AD samples.

\section{Conclusion}

Altered glycosylation pattern in purified ACT from the peripheral blood of $\mathrm{AD}$ maight be ascribed to an increased inflammation of the brain or an altered glycation process of ACT along with several other brain proteins in $\mathrm{AD}$.

Our findings suggest that low content of terminal GlcNac glycans and sialic acid in peripheral ACT might be a marker of diseases progression and it might be used in clinical trials as surrogate marker of clinical efficacy.

\section{Acknowledgements \\ This research was supported by Italian Ministry of Research and University and Fondazione Banca del Monte di Bologna e Ravenna, Bologna, Italy. This article has been published as part of Immunity \& Ageing Volume 7 Supplement 1, 2010: Predictive medicine, new diagnostic tools and prevention of diseases. The full contents of the supplement are available online at http://www.immunityageing.com/content/7/S1}

\section{List of abbreviations}

AD: alzheimer's disease; ACT: alpha-1-antichymotrypsin; CTR: controls; IL $1 \alpha$ : Interleukin 1 $\alpha$; IL-1ß: Interleukin 1ß; IL-6: Interleukin 6; TNF- $\alpha$ : tumor necrosis factor $\alpha$; A $\beta$ : beta-amyloid; CSF: cerebrospinal fluid; PNGase F: N-Glycanase digestion from Flavobacterium meningosepticum; GlcNac: N-acetyl glucosamine; GalNac: terminal N-acetyl galactosamine; Gal/GalNac: Galactose/N-acetyl galactosamine.

\section{Authors' contribution}

MI and MM performed ACT ELISA assay and ACT GlycoArray; $E P, M C$ and IC purification of ACT and writing article;

GDS and FL Conception and Design and writing article

\section{Competing interests}

The authors declare that they have no competing interests.

Published: 16 December 2010

\section{References}

1. Katzman RN: Medical progress: Alzheimer's disease. N Engl J Med 1996, 274:964-973.

2. Abraham CR, Selkoe DJ, Potter H: Immunochemical identification of the serine protease inhibitor alpha 1-antichymotrypsin in the brain amyloid deposits of Alzheimer's disease. Cell 1998, 52:487-501.

3. Travis J, Salvesen GS: Human plasma proteinase inhibitors. Annu Rev Biochem 1983, 52:655-709.

4. Styren SD, Kamboh MI, DeKosky ST: Expression of differential immune factors in temporal cortex and cerebellum: the role of alpha-1antichymotrypsin, apolipoprotein $\mathrm{E}$, and reactive glia in the progression of Alzheimer's disease. J Comp Neurol 1998, 396:511-520.

5. Eriksson S, Janciauskiene $S$, Lannfelt L: Alpha 1-antichymotrypsin regulates Alzheimer beta-amyloid peptide fibril formation. Proc Natl Acad Sci U S A 1995, 92:2313-2317.

6. Fraser PE, Nguyen JT, McLachlan DR, Abraham CR, Kirschner DA: Alpha 1antichymotrypsin binding to Alzheimer $A$ beta peptides is sequence specific and induces fibril disaggregation in vitro. J Neurochem 1993, 61:298-305.

7. Potter $H$, Wefes IM, Nilsson LN: The inflammation-induced pathological chaperones ACT and ApoE are necessary catalysts of Alzheimer amyloid formation. Neurobiol Aging 2001, 22:923-930.

8. Nilsson LN, Arendash GW, Leighty RE, Costa DA, Low MA, Garcia MF, Cracciolo JR, Rojiani A, Wu X, Bales KR, Paul SM, Potter H: Cognitive impairment in PDAPP mice depends on ApoE and ACT-catalyzed amyloid formation. Neurobiol Aging 2004, 25:1153-1167.

9. Padmanabhan J, Levy M, Dickson DW, Potter H: Alpha1-antichymotrypsin, an inflammatory protein overexpressed in Alzheimer's disease brain, induces tau phosphorylation in neurons. Brain 2006, 129:3020-3034.

10. Kordula T, Bugno M, Rydel RE, Travis J: Mechanism of interleukin-1- and tumor necrosis factor alpha-dependent regulation of the alpha 1antichymotrypsin gene in human astrocytes. J Neurosci 2000, 20:7510-7516.

11. Chiappelli $M$, Tumini $E$, Porcellini $E$, Licastro F: Impaired regulation of immune responses in cognitive decline and Alzheimer's disease: lessons from genetic association studies. Expert Rev Neurother 2006, 6:1327-1336.

12. Licastro F, Morini MC, Davis LJ, Malpassi P, Cucinotta D, Parente R, Melotti C, Savorani G: Increased chemiluminescence response of neutrophils from the peripheral blood of patients with senile dementia of the Alzheimer's type. J Neuroimmunol 1994, 51:21-26.

13. Licastro F, Parnetti L, Morini MC, Davis LJ, Cucinotta D, Gaiti A, Senin U: Acute phase reactant alpha 1-antichymotrypsin is increased in cerebrospinal fluid and serum of patients with probable Alzheimer disease. Alzheimer Dis Assoc Disord 1995, 9:112-118.

14. Matsubara E, Amari M, Shoji M, Harigaya Y, Yamaguchi H, Okamoto K, Hirai S: Serum concentration of alpha 1-antichymotrypsin is elevated in patients with senile dementia of the Alzheimer type. Prog Clin Biol Res 1989, 317:707-714

15. Licastro F, Davis LJ, Morini MC, Cucinotta D, Savorani G: Cerebrospinal fluid of patients with senile dementia of Alzheimer's type shows an increased inhibition of alpha-chymotrypsin. Alzheimer Dis Assoc Disord 1994, 8:241-249.

16. Licastro F, Pedrini S, Ferri C, Casadei V, Govoni M, Pession A, Sciacca FL, Veglia F, Annoni G, Bonafè M, Olivieri F, Franceschi C, Grimaldi LM: Gene polymorphism affecting alpha1-antichymotrypsin and interleukin-1 plasma levels increases Alzheimer's disease risk. Ann Neurol 2000, 48:388-391.

17. Furby A, Leys D, Delacourte A, Buee L, Soetaert G, Petit H: Are alpha-1antichymotrypsin and inter-alpha-trypsin inhibitor peripheral markers of Alzheimer's disease? J Neurol Neurosurg Psychiatry 1991, 54:469.

18. Lanzrein AS, Johnston CM, Perry VH, Jobst KA, King EM, Smith AD: Longitudinal study of inflammatory factors in serum, cerebrospinal fluid, and brain tissue in Alzheimer disease: interleukin-1 beta, interleukin- 6 , interleukin-1 receptor antagonist, tumor necrosis factor-alpha, the soluble tumor necrosis factor receptors I and II, and alpha1antichymotrypsin. Alzheimer Dis Assoc Disord 1998, 12:215-227. 
19. Porcellini E, Davis EJ, Chiappelli M, lanni E, Di Stefano G, Forti P, Ravaglia G, Licastro F: Elevated plasma levels of alpha-1-anti-chymotrypsin in agerelated cognitive decline and Alzheimer's disease: a potential therapeutic target. Curr Pharm Des 2008, 14:2659-2664.

20. Dik MG, Jonker C, Hack CE, Smit JH, Comijs HC, Eikelenboom P: Serum inflammatory proteins and cognitive decline in older persons. Neurology 2005, 64:1371-1377.

21. McGeer PL, McGeer EG: The inflammatory response system of brain: implications for therapy of Alzheimer and other neurodegenerative diseases. Brain Res Brain Res Rev 1995, 21:195-218.

22. Chavan MM, Kawle PD, Mehta NG: Increased sialylation and defucosylation of plasma proteins are early events in the acute phase response. Glycobiology 2005, 15:838-848.

23. Gornik O, Lauc G: Glycosylation of serum proteins in inflammatory diseases. Dis Markers 2008, 25:267-278.

24. Hachulla E, Laine A, Hayem A: Alpha 1-antichymotrypsin microheterogeneity in crossed immunoaffinoelectrophoresis with free concanavalin A: a useful diagnostic tool in inflammatory syndrome. Clin Chem 1988, 34:911-915.

25. Laine A, Hachulla E, Strecker G, Michalski JC, Wieruszeski JM: Structure determination of the glycans of human-serum alpha 1-antichymotrypsin using $1 \mathrm{H}-\mathrm{NMR}$ spectroscopy and deglycosylation by N-glycanase. Eur J Biochem 1991, 197:209-215.

26. Zhang $H$, Li XJ, Martin DB, Aebersold R: Identification and quantification of N-linked glycoproteins using hydrazide chemistry, stable isotope labeling and mass spectrometry. Nat Biotechnol 2003, 21:660-666.

27. Hrycaj P, Nayyar S, Stanworth DR, Müller W: Microheterogeneity of alpha 1 -antitrypsin in relation to the concentration of its complex with immunoglobulin A in the sera of patients with rheumatoid arthritis. Clin Exp Rheumatol 1996, 14:119-123.

28. Saldova R, Royle L, Radcliffe CM, Abd Hamid UM, Evans R, Arnold JN, Banks RE, Hutson R, Harvey DJ, Antrobus R, Petrescu SM, Dwek RA, Rudd PM: Ovarian cancer is associated with changes in glycosylation in both acute-phase proteins and IgG. Glycobiology 2007, 17:1344-1356.

29. Tajiri M, Ohyama C, Wada Y: Oligosaccharide profiles of the prostate specific antigen in free and complexed forms from the prostate cancer patient serum and in seminal plasma: a glycopeptide approach. Glycobiology 2008, 18:2-8

30. Farquhar MJ, Gray CW, Breen KC: The over-expression of the wild type or mutant forms of the presenilin-1 protein alters glycoprotein processing in a human neuroblastoma cell line. Neurosci Lett 2003, 346:53-56.

31. Botella-Lopez A, De Madaria E, Jover R, Bataller R, Sancho-Bru P, Candela A, Compañ A, Pérez-Mateo M, Martinez S, Sáez-Valero J: Reelin is overexpressed in the liver and plasma of bile duct ligated rats and its levels and glycosylation are altered in plasma of humans with cirrhosis. Int J Biochem Cell Biol 2008, 40:766-775.

32. Ravaglia G, Forti P, Maioli F, Scali RC, Arnone G, Talerico T, Pantieri T, Nativio V, Mantovani V, Bianchin M: Common polymorphisms in methylenetetrahydrofolate reductase (MTHFR): relationships with plasma homocysteine concentrations and cognitive status in elderly northern italian subjects. Arch Gerontol Geriatr Suppl 2004, 9:339-348,

33. McKhann G, Drachman D, Folstein M, Katzman R, Price D, Stadlan EM: Clinical diagnosis of Alzheimer's disease: report of the NINCDS-ADRDA Work Group under the auspices of Department of Health and Human Services Task Force on Alzheimer's Disease. Neurology 1984, 34:939-944.

34. American Psychiatric Association: Diagnostic and statistical manual of mental disorders: DSM-III-R. Washington (DC): American Psychiatric Association; 3199758.

35. Doody RS, Massman P, Dunn JK: A method for estimating progression rates in Alzheimer disease. Arch Neurol 2001, 58:449-454.

36. Apweiler $\mathrm{R}$, Hermjakob $\mathrm{H}$, Sharon $\mathrm{N}$ : On the frequency of protein glycosylation, as deduced from analysis of the SWISS-PROT database. Biochim Biophys Acta 1999, 1473:4-8.

37. Licastro F, Campbell IL, Kincaid C, Veinbergs I, Van Uden E, Rockenstein E, Mallory M, Gilbert JR, Masliah E: A role for apoE in regulating the levels of alpha-1-antichymotrypsin in the aging mouse brain and in Alzheimer's disease. Am J Pathol 1999, 155:869-875.

38. Aronsen KF, Ekelund G, Kindmark CO, Laurell CB: Sequential changes of plasma proteins after surgical trauma. Scand I Clin Lab Invest Suppl 1972, 124:127-136.
39. Licastro F, Pedrini S, Caputo L, Annoni G, Davis L, Ferri C, Casadei V, Grimaldi LM: Increased plasma levels of interleukin-1, interleukin- 6 and alpha-1-antichymotrypsin in patients with Alzheimer's disease: peripheral inflammation or signals from the brain? I Neuroimmunol 2000, 103:97-102.

40. Damgaard AM, Heegard PM, Hansen JE, Bøg-Hansen TG: The microheterogeneity of the acute phase reactant alpha-1antichymotrypsin in testicular and colorectal cancer. Protides of the Biological Fluids 1986, 34:449-452.

41. Raynes J: Variations in the relative proportions of microheterogeneous forms of plasma glycoproteins in pregnancy and disease. Biomed Pharmacother 1982, 36:77-86.

42. Rosenfeld R, Bangio H, Gerwig GJ, Rosenberg R, Aloni R, Cohen Y, Amor Y, Plaschkes I, Kamerling JP, Maya RB: A lectin array-based methodology for the analysis of protein glycosylation. J Biochem Biophys Methods 2007, 70:415-426.

43. Saez-Valero J, Sberna G, McLean CA, Small DH: Molecular Isoform Distribution and Glycosylation of Acetylcholinesterase Are Altered in Brain and Cerebrospinal Fluid of Patients with Alzheimer's Disease. Journal of Neurochemistry 1999, 72:1600-1608.

doi:10.1186/1742-4933-7-S1-S6

Cite this article as: lanni et al:: Altered glycosylation profile of purified plasma ACT from Alzheimer's disease. Immunity \& Ageing 2010 7(Suppl 1):S6.

\section{Submit your next manuscript to BioMed Central and take full advantage of:}

- Convenient online submission

- Thorough peer review

- No space constraints or color figure charges

- Immediate publication on acceptance

- Inclusion in PubMed, CAS, Scopus and Google Scholar

- Research which is freely available for redistribution 